\title{
Gait velocity and step length may discriminate active from sedentary elderly women
}

\author{
Velocidade de marcha e comprimento de passada pode discriminar mulheres \\ idosas ativas das sedentárias
}

\section{Bruno de Souza Moreira' \\ Renata Noce Kirkwood ${ }^{1}$ \\ Andréa de Jesus Lopes ${ }^{2}$ \\ Rosângela Corrêa Dias ${ }^{1}$ \\ Rosana Ferreira Sampaio ${ }^{1}$}

${ }^{1}$ Physical Therapy Department, Universidade Federal de Minas Gerais, Minas Gerais, Brazil

2 Physical Therapy Department, Centro Universitário Newton Paiva, Belo Horizonte, Minas Gerais, Brazil

\section{ENDEREÇO PARA CORRESPONDÊNCIA}

Renata Noce Kirkwood, Ph.D. Universidade Federal de Minas Gerais Physical Therapy Department Antonio Carlos Avenue, 6627 Belo Horizonte, Minas Gerais, Brazil 31270-901

renata.kirkwood@gmail.com

$$
\begin{array}{ll}
\text { - Recebido: } & 09 / 06 / 2011 \\
\text { - Re-submissão: } & 12 / 10 / 2011 \\
\text { - Aceito: } & 15 / 10 / 2011
\end{array}
$$

\begin{abstract}
Gait is an important functional activity that elderly individuals used to stay active and be able to perform their daily living tasks. The purpose of this study was to determine what gait parameters could discriminate a group of community-dwelling elderly women regularly enrolled in a physical exercise program compared to a paired sedentary group. Participated 145 women (65 to 83 years) separated into two groups based on the guidelines of the American College of Sports Medicine (2007): sedentary $(n=52)$ and active $(n=93)$. Eight gait variables were recorded using the GAITRite ${ }^{\circledR}$ system (velocity normalized by length of lower limbs, stance time, swing time, double support time, step time, step length, base width and cadence). Factorial analysis followed by discriminant analysis was performed to determine which variables could best discriminate the sedentary group from the active group. Factorial analysis resulted in 4 factors which explained $98.7 \%$ of the data variability. Factor 3 (composed of step length and velocity) explained $11.8 \%$ of the data variability and was the only factor to discriminate the groups. When the original variables from Factor 3 were analyzed, gait velocity was the most discriminant variable, with a much higher discriminant coefficient $(-0.999)$ than step length (-0.022). Gait velocity and step length could be used as a screening tool to discriminate between active and sedentary elderly women.
\end{abstract}

Keywords: Gait; Physical activity; Elderly; Measurement.

\section{Resumo}

A marcha é uma atividade funcional importante que é utilizada por indivíduos idosos para se manterem ativos e capazes de realizar suas tarefas diárias. O objetivo deste estudo foi determinar quais parâmetros da marcha podem discriminar um grupo de mulheres idosas envolvidas regularmente em um programa de exercício físico comparado com um grupo de idosas sedentárias. Foram avaliadas 145 idosas (65 a 83 anos) divididas em dois grupos de acordo com as diretrizes do American College of Sports Medicine (2007): sedentárias ( $n=$ 52 ) e ativas $(n=93)$. Oito variáveis da marcha foram registradas usando o sistema GAITRite ${ }^{\circledR}$ (velocidade normalizada pelo comprimento dos membros inferiores, tempo da fase de apoio e de oscilação, tempo de duplo apoio, tempo do passo, comprimento do passo, base de suporte e cadência). Foi realizada uma análise fatorial seguida de análise discriminante para determinar quais variáveis poderiam discriminar melhor o grupo de idosas sedentárias das ativas. A análise fatorial resultou em 4 fatores que explicaram 98,7\% da variabilidade dos dados. O fator 3 (composto pelo comprimento do passo e velocidade da marcha) explicou $11,8 \%$ da variabilidade dos dados, sendo o único fator discriminante entre os grupos. Quando as variáveis originais do fator 3 foram analisadas, a velocidade da marcha apresentou maior poder de discriminação, com um coeficiente discriminante muito maior $(-0,999)$ do que o comprimento do passo $(-0,022)$. A velocidade da marcha e o comprimento do passo podem ser usados na discriminação entre idosas ativas e sedentárias.

Palavras-chave: Marcha; Atividade física; Idoso; Medida. 


\section{INTRODUCTION}

The world population is ageing. This global phenomenon has been observed in Brazil since the sixties, because of the increase of life expectancy and the decrease of the fecundity rates $^{1}$. By 2025, Brazil will have the sixth largest population of elderly individuals in the world ${ }^{2}$, which is expected to surpass $22.7 \%$ of the total population by $2050^{3}$. Projections indicate that the world will have two billion people over 65 years of age by 2050; the United States is expected to have 88 million and Europe will be the continent with the largest contingent of elderly individuals - approximately 263 million ${ }^{4}$. Thus, the growing number of older adults will certainly increase the demands over the public health system.

Ageing is associated with a cascade of morphological and physiological changes that naturally predisposes older adults to progressive functional decline, morbidity, disability, poor quality of life and increased mortality ${ }^{5}$. Adopting an active lifestyle is a healthy way to slow down physiological changes and the decline in the function of biological systems stemming from ageing ${ }^{2,6}$. Several studies have shown the effectiveness of physical exercise programs designed for the elderly population to improve flexibility, muscle strength, balance and aerobic capacity ${ }^{7-9}$. Physical exercise also reduces the risk of coronary heart disease, hypertension, type II diabetes, osteoporosis, obesity and falls ${ }^{10}$. Among all these conditions, fall is considered one of the main causes of functional impairment in elderly individuals ${ }^{11}$.

Gait is an important functional activity that elderly individuals used to stay active and be able to perform their daily living tasks. Age may affect several characteristics of gait including speed (and its contributors, step length and cadence), step width and double support phase ${ }^{12}$. In recent years in Brazil, with the intention of minimizing the alterations stemming from ageing process, a lot of communities have been implanted physical exercise programs targeted to the elderly population. The activities are guided by health care professionals such as physiotherapists, physical educators and physicians. The aim is to maintain or improve physical fitness parameters such as muscle strength, flexibility, aerobic conditioning, balance as well as keep people's social interaction. The programs involve sessions of different types of exercises, but walking is an important part of the sections, besides being a choice of physical exercise for a lot of people independent of their age.

The effects of physical exercise on gait parameters in elderly individuals have been demonstrated in a few numbers of clinical trials, but the results are yet conflicting. For example, Lord et al. ${ }^{13}$ demonstrated that a combined exercise program increased walking speed, cadence and stride length in community-dwelling elderly women aged 60 to 83 years. Similarly, Lopopolo et al. ${ }^{14}$ demonstrated that strength training combined with aerobic exercises, had a significant and positive effect on habitual walking speed in elderly subjects. Conversely, other studies failed to report the benefits of a physical exercise program on gait parameters in older adults ${ }^{15,16}$.

One of the limitations is the different gait variables that have been investigated, resulting in different conclusions among the studies. Other important problem not addressed in the most of the studies, is the strength of the correlation between the gait variables, described as collinearity. Therefore, a more appropriated statistical technique, such as factor analysis, should be applied to account for the correlation between the gait variables and define the parameters that could better identify changes in the gait of elderly subjects enrolled in physical exercise programs. Thus, the aim of the present study was to determine what gait parameters could discriminate a group of community-dwelling elderly women regularly enrolled in a physical exercise program compared to a paired sedentary group.

\section{METHODS}

\section{Sample}

An observational study with a convenience sample of 145 community-dwelling elderly individuals, aged 65 to 83 years, recruited at senior citizen centers and senior citizen physical activity groups was performed. The participants were separated into two groups, sedentary $(n=52)$ and active ( =93), based on the intensity, duration and frequency of aerobic exercise, following the recommendations of the American College of Sports Medicine (ACSM) for the promotion and maintenance of health among elderly individuals ${ }^{6}$. The active group performed either combined exercises (combination of aerobic, strengthening, balance and stretching exercises) or exclusively aerobic exercises (walking, treadmill, hydrogymnastics, dance or swimming).

The following were the inclusion criteria for both groups: A) Female gender; B) Age 65 years or older; C) Living in the community; D) Independent gait (without gait assistance device). The following were the exclusion criteria for both groups: A) Cognitive impairment detectable by the Mini-Mental State Examination (MMSE) using cutoff points based on the degree of education ${ }^{17}$. The MMSE is composed of questions grouped into seven categories, with the aim of assessing specific cognitive functions: time orientation, spatial orientation, registration, attention and calculation, recall, language aspects and visual constructive capacity. The MMSE score ranges from 0 to 30 points, with higher scores denoting better performance. $B$ ) Limited functional mobility identified through the Timed Up and Go (TUG) test using cutoff points based on age group ${ }^{18}$. The TUG quantifies the amount of time needed for an individual to stand up from a chair, walk a distance of three meters, turn around, walk back to the chair and sit down again ${ }^{19}$. Volunteers between 65 and 69 years of age that spent more than 9.0 seconds, those between 70 and 79 years of age that spent more than 10.2 seconds and those aged 80 years or older that spent more 12.7 seconds performing the activity, were excluded from the study group ${ }^{18}$.

The inclusion criterion for the group of active individuals was the practice of aerobic exercise of moderate intensity for at least 30 minutes five days a week or of high intensity for at least 20 minutes three days a week ${ }^{6}$ in at least the previous three months at the beginning of the study. The volunteers who reported not practicing any type of physical activity or performed physical exercise at an intensity, duration and frequency lower than that recommended by the ACSM were included in the group of sedentary individuals.

The present study received approval from the ethics committee of the Universidade Federal de Minas Gerais, Brazil, under process number ETIC 442/08 in compliance with the norms established in Resolution 196/96 of the Brazilian National Board of Health regarding studies involving human beings. The volunteers received orientation on all procedures and, after agreeing to participate, signed terms of informed consent.

\section{Procedures}

A structured questionnaire was first administered for the acquisition of socio-demographic and clinical data of the vo- 
lunteers: age, number of comorbidities, medications in use, schooling and information on the practice of physical activity. Volunteers who reported practicing physical activities were asked about the type of activity, frequency (days per week), duration (minutes per day/session), intensity (low, moderate or high - assessed based on subjective perception of effort) and overall duration of the practice (months or years). Anthropometric measurements were also collected: body mass, height and length of both lower limbs (from greater trochanter of the femur to the ground, passing over the lateral malleolus). The body mass index was calculated from body mass and height. The elderly women were assessed in the following sequence: cognitive level using the MMSE, functional mobility using the TUG and temporal-spatial gait parameters using the GAITRite ${ }^{\circledR}$ system (CIR Systems Inc., Clifton, NJ, USA). This instrument consists of a rubber electronic mat 5.74 meters in length, $91 \mathrm{~cm}$ in width and $0.6 \mathrm{~cm}$ in thickness that contains 18,432 embedded sensors spaced $1.27 \mathrm{~cm}$ apart. As the individual walks upon the mat, the system captures the geometry and contact of the foot with the ground in function of time and distance. The capture frequency of the gait parameters was $120 \mathrm{~Hz}$. The GAITRite ${ }^{\circledR}$ is a widely used system in clinical and research settings, and high concurrent validity against a gold standard three-dimensional motional analysis system ${ }^{20}$ and excellent test-retest reliability in older people has previously been reported ${ }^{21}$.

For the execution of the TUG, a standardized, armless chair with a height of $40 \mathrm{~cm}$ or $44 \mathrm{~cm}$ was used. The volunteers were instructed not to use their upper limbs as an aid for standing up and to walk as fast as safely possible. Upon the command "go", the volunteer began the movement. The chronometer was activated once the volunteer's back lost contact with the back of the chair and was stopped when the individual had completed the maneuver and her back made contact with the back of the chair again. A trial run was first performed for the individual to become familiarized with the test. The participant then performed the test twice and the final result was calculated as the mean of the two executions.

For the assessment of gait, the participants were instructed to walk upon the mat at their habitual (self-selected) pace wearing comfortable shoes. The beginning and end of the course were marked by cones placed two meters from the edge of the mat for initial acceleration and final deceleration. The volunteer was positioned next to the cone and the system was activated. Upon the command "go", the volunteer walked toward the other cone and turned around; a new command was given and the volunteer returned to the initial cone. Six walks were recorded for each individual.

\section{Reduction of Data}

Temporal and spatial gait data were processed by the GAITRite ${ }^{\circledast}$ system, which permitting editing and selecting the desired plantar impressions from the active area of the carpet. The six trials were added using a resource from the software denominated Manually Add Walks to Tests, thereby creating a single file for all the walks together. The variables investigated were as follow: 1) Gait velocity normalized by the average leg length was obtained directly from the GAITRite ${ }^{\circledR}$ system after dividing the velocity by the average leg length (distance from the greater trochanter to floor computed from left leg length + right leg length/2); 2) Stance time, the weight-bearing portion of each gait cycle; 3) Swing time, the non-weight-bearing portion of the cycle; 4) Double support time, two periods of gait cycle when both feet are in contact with the floor; 5) Step time, time elapsed from first contact of one foot to first contact of the other foot; 6) Step length, measured along the line of progression, distance from the heel center of the current footprint to the heel center of the previous footprint on the opposite foot; 7) Base width, vertical distance from heel center of one footprint to the line of progression formed by two footprints of the other foot; and 8) Cadence, number of steps per minute.

\section{Statistical Analysis}

The Mann-Whitney test and Student's t-test with Bonferroni's correction were used to compare anthropometric, demographic and clinical data. Factor analysis with varimax rotation was conducted in the temporal and spatial gait parameters. After the independent factors were identified, a discriminant analysis was conducted to determine which factor(s) could discriminate the groups (active/sedentary). Then, the original variables that composed those factors were submitted to further discriminant analysis to determine the contribution of each gait variable to the discriminant function. All the data were analyzed with a significance level of 0.05 .

\section{RESULTS}

Fifty-two sedentary women with an average age of 71.3 (5.5) years and 93 active women with an average age of 71.3 (4.6) years participated in the study; this difference was not significant $(U=2379.0, p=0.872)$. No significant differences between groups were found with regard to other anthropometric, demographic and clinical data (Table 1). The active group reported practicing physical exercises three to seven days a week with an average duration of one hour per day. The majority of individuals in this group (93.5\%) participated in supervised physical exercise programs offered by the city of Belo Horizonte, Brazil. The mean overall duration of the practice of physical activity was eight years (ranging from 3 months to 20 years). Among the 93 active elderly women, only six had been exercising for less than one year.

Table 2 displays the values of the spatial and temporal parameters for both groups. The sample adequacy measure (Kaiser-Meyer-Olkin), which determines the degree of inter-correlation between variables and the adequacy of the factor analysis was 0.709 , indicating that the data were adequate for the analysis. Likewise, the Bartlett sphericity test was significant $(p<0.000)$, indicating a sufficient correlation between the response variable to proceed with the factor analysis.

Factor analysis returned four factors that explained $98.7 \%$ of the variance (Table 3). Factor 1, which explained $57.4 \%$ of the variance in the data, included the variables swing time, cadence, step time and stance time and therefore represented the rhythm dimension. Factor 2 explained $20.5 \%$ of the variance and was made up of double support time, thereby representing the stance dimension. Factor 3 explained $11.8 \%$ of the variance and represented the distance dimension, composed of normalized velocity and step length. Factor 4 (base width) explained $9.0 \%$ of the variance and represented the support dimension. The validation of the factor analysis was conducted using random samples of 80 and 100 individuals and achieved similar results to those in the initial factor analysis. Validation with 80 individuals revealed a KMO value of 0.724 and a significant Bartlett sphericity test result $(p<0.000)$, with four factors explaining $94 \%$ of the variance in the data.

Discriminant analysis was then conducted to determine what factors best discriminated the two groups of active and 


\begin{tabular}{lccl}
\hline Variables & $\begin{array}{c}\text { Sedentary } \\
\text { Mean (SD) }\end{array}$ & $\begin{array}{c}\text { Active } \\
\text { Mean (SD) }\end{array}$ & $P$-value \\
\hline Age (years) & $71.3(5.5)$ & $71.3(4.6)$ & $0.872^{\mathrm{a}}$ \\
Height $(\mathrm{cm})$ & $154.5(6.0)$ & $154.2(5.6)$ & $0.729^{\mathrm{b}}$ \\
BMI $\left(\mathrm{kg} / \mathrm{m}^{2}\right)$ & $27.3(5.0)$ & $27.1(4.2)$ & $0.805^{\mathrm{b}}$ \\
Education (years) & $7.1(4.9)$ & $6.4(4.8)$ & $0.269^{\mathrm{a}}$ \\
Comorbidity (N) & $2.7(2.0)$ & $2.3(1.7)$ & $0.244^{\mathrm{a}}$ \\
Medication (N) & $3.0(2.2)$ & $2.8(2.1)$ & $0.525^{\mathrm{a}}$ \\
MMSE (range 0-30) & $27.0(3.2)$ & $27.0(2.7)$ & $0.597^{\mathrm{a}}$ \\
TUG (s) & $8.5(0.8)$ & $8.2(0.9)$ & $0.028^{\mathrm{b}}$ \\
\hline
\end{tabular}

SD: standard deviation; BMI: body mass index; MMSE: mini-mental state examination; TUG: timed up and go test; $\mathrm{N}$ : number; $\mathrm{cm}$ : centimeter; s: second; $\mathrm{kg} / \mathrm{m}^{2}$ : kilogram per square meter.

${ }^{a}$ Mann -Whitney test with Bonferroni correction significant at $p<0.01$.

${ }^{\mathrm{b}}$ Independent $\mathrm{t}$ test with Bonferroni correction significant at $p<0.017$.

\section{Table 2}

Temporal and spatial gait parameters between the sedentary $(n=52)$ and active $(n=93)$ elderly groups

\begin{tabular}{lcc}
\hline Variables & $\begin{array}{c}\text { Sedentary } \\
\text { Mean (SD) }\end{array}$ & $\begin{array}{c}\text { Active } \\
\text { Mean (SD) }\end{array}$ \\
\hline Swing time (s) & $0.39(0.02)$ & $0.39(0.03)$ \\
Cadence (steps/min) & $119.5(7.6)$ & $121.6(7.2)$ \\
Step time (s) & $0.50(0.03)$ & $0.50(0.03)$ \\
Stance time (s) & $0.62(0.05)$ & $0.60(0.04)$ \\
Double support time (s) & $0.23(0.04)$ & $0.22(0.03)$ \\
Step length (cm) & $62.4(5.6)$ & $64.6(6.0)$ \\
Velocity (m/s) & $1.52(0.17)$ & $1.61(0.19)$ \\
Base width (cm) & $7.6(3.1)$ & $7.3(2.3)$ \\
\hline
\end{tabular}

SD: standard deviation; s: second; $\mathrm{cm}$ : centimeter; $\mathrm{m} / \mathrm{s}$ : meter per second; steps/min: steps per minute.

Principal components with varimax rotation factor matrix $(n=145)$

\begin{tabular}{lccccc}
\hline \multirow{2}{*}{ Variables } & $\begin{array}{c}\text { Factor 1 } \\
\text { Rhythm }\end{array}$ & $\begin{array}{c}\text { Factor 2 } \\
\text { Stance }\end{array}$ & $\begin{array}{c}\text { Factor 3 } \\
\text { Distance }\end{array}$ & $\begin{array}{c}\text { Factor 4 } \\
\text { Support }\end{array}$ & Communality \\
\hline Swing time (s) & $\mathbf{0 . 9 8 5}$ & -0.156 & 0.023 & -0.030 & 0.997 \\
Cadence (steps/min) & $\mathbf{- 0 . 9 0 2}$ & -0.399 & 0.150 & -0.014 & 0.996 \\
Step time (s) & $\mathbf{0 . 8 9 9}$ & 0.405 & -0.156 & 0.016 & 0.998 \\
Stance time (s) & $\mathbf{0 . 6 9 7}$ & 0.673 & -0.237 & 0.048 & 0.998 \\
Double support time (s) & 0.138 & $\mathbf{0 . 9 4 2}$ & -0.293 & 0.081 & 0.999 \\
Step length (cm) & 0.052 & -0.175 & $\mathbf{0 . 9 6 7}$ & -0.023 & 0.969 \\
Velocity (m/s) & -0.480 & -0.303 & $\mathbf{0 . 7 7 9}$ & -0.114 & 0.942 \\
Base width (cm) & -0.004 & 0.065 & -0.063 & $\mathbf{0 . 9 9 6}$ & 1.000 \\
\hline
\end{tabular}

$\mathrm{s}$ : second; cm: centimeter; $\mathrm{m} / \mathrm{s}$ : meter per second; steps/min: steps per minute.

sedentary elderly women. Box's M covariance test indicated equality between the matrices of both groups ( $p=0.432$ ). WiIks' lambda was significant $(p=0.032)$, thereby rejecting the null hypothesis that the value of the discriminant function was the same for both groups. The results revealed that only Factor 3 could classify correctly $59.3 \%(86 / 145)$ of the observations between the groups.

The original variables from Factor 3 (normalized gait ve- 
locity and step length) were then standardized, since the two variables were on different scales, by dividing them by their global standard deviation. Fisher's linear coefficient was then conducted obtained by transformation of the linear coefficients into an interval spanning -1 to 1 to simplify the results. Normalized gait velocity achieved a much higher discrimination coefficient than step length and was therefore the most important variable in the discrimination of the groups in active and sedentary elderly women (Table 4). On average, the active group walked at a greater gait velocity $(1.61 \mathrm{~m} / \mathrm{s} X 1.52$ $\mathrm{m} / \mathrm{s})$ and step length $(64.6 \mathrm{~cm} \mathrm{X} 62.4 \mathrm{~cm})$ than the sedentary group.

\section{DISCUSSION}

The aim of the present study was to determine what gait parameters, from a group of active elderly women enrolled in a regular practice of physical exercise, could discriminate them from a paired group of sedentary community-dwelling women. The discriminant model determined that gait velocity and step length could classify active and sedentary elderly women $59.3 \%$ of the time, with gait velocity being the major contributor to the model. Although, we can misclassify $41 \%$ of the elderly subjects, this study shows the importance of adding these variables as part of our clinical measures.

The gait velocity difference found between the two groups was $0.09 \mathrm{~m} / \mathrm{s}$, which exceeds the $0.05 \mathrm{~m} / \mathrm{s}$ threshold considered as clinically meaningful ${ }^{22}$. Gait velocity is influenced by physical characteristics, such as age, gender, height, disease and physical fitness ${ }^{23}$. In the present study, the groups were similar with regard to age, height and number of comorbidities. Thus, physical fitness likely accounted for the differences found between groups. Other factors such as lower limb strength, balance, reaction time, vision, pain and emotional well-being may also affect gait velocity ${ }^{24}$. In addition, the peak oxygen uptake ( $\mathrm{VO}_{2}$ peak), important indicator of aerobic fitness, is also strongly associated with habitual gait velocity in elderly people ${ }^{25}$. A recent study involving a group of elderly individuals found that the factors most strongly associated to gait velocity were quadriceps strength and reaction time ${ }^{26}$. It is therefore possible that the routine physical exercise programs indeed contributed to maintain the elderly women healthy, strong and less affected by the ageing process. However, due to the observational nature of the present study, no cause-and-effect relationship can be stated and further investigations are needed to clarify this issue.

As a screening tool, it is recommended that gait velocity should be used routinely in clinical settings. It is known that a reduction in gait velocity may represent an early clinical or sub-clinical manifestation of diseases in multiple systems and gait performance depends on the maintenance of the normal function of different physiological systems working in a highly integrated and coordinated manner ${ }^{27,28}$. Moreover, the literature has also shown that a reduction in gait velocity is asso- ciated to an increased risk of falls among elderly individuals and is therefore an important variable in the identification of individuals at high risk and who potentially require preventive interventions ${ }^{29}$.

The contribution of the step length variable in the model cannot be discarded. Although with a lower power of discrimination, step length is easy to measure in clinical settings with simple instruments such as paper and ink and may perhaps be used together with gait velocity in the discrimination of active and sedentary elderly individuals. Regarding the other gait variables investigated that failed to contribute to the model, the results of the factorial analysis illustrated that data reduction was satisfactory and that gait velocity and step length are the key variables to account when developing a study.

One of the limitations of the present study was the fact that the variables related to the practice of physical exercise (intensity, frequency and duration) were based on self-reports from the volunteers, which did not allow adequate control. Normally, studies on this topic are of a clinical design, in which the individuals are assessed prior to and following a physical activity program, which offers greater control over the parameters. However, the practice of physical exercise has been offered regularly through social programs with the aim of demonstrating to the elderly public the importance of exercising as well as to encourage elderly individuals to interact socially. Therefore, knowledge on the benefits of these programs may assist health care professionals and public administrators in the design of programs that encourage the practice of physical exercises with the aim of health promotion and disease prevention.

Another factor to consider was the evaluation of women alone, with no participation of the male gender. This characteristic of the sample was due to the very small number of elderly men at the senior citizen centers and physical activity groups invited to participate in the study. Future studies should investigate the effect of regular physical activity on gait among elderly male individuals, as the sex factor affects temporal-spatial variables of gait ${ }^{12}$.

The strong points of the present study included the fact that the data were rigorously collected by a trained staff using standardized protocols and obtained by means of sophisticated instruments. The multivariate statistical analysis was an important aspect of the study. Gait is a complex motor activity with a large volume of highly correlated temporal and spatial variables. Thus, the application of appropriate statistical methods is important for determining the independent effect of the variables, considering their inter-correlations ${ }^{30}$. The use of factor analysis was advantageous, as it reduced the number of variables into factors that were not interrelated ${ }^{30}$. Once such factors were identified, discriminant analysis was performed on the corresponding variables to determine what variables best discriminated sedentary and active elderly women.

In summary, the present study contributes to the identi-

\begin{tabular}{lc}
\hline Variables & Normalized Discriminant Function \\
\hline Step length $(\mathrm{cm})$ & -0.022 \\
Velocity $(\mathrm{m} / \mathrm{s})$ & $\mathbf{- 0 . 9 9 9 *}$ \\
\hline cm: centimeter; m/s:meter per second \\
*Normalized velocity with higher discriminant value between groups.
\end{tabular}


fication of the temporal-spatial gait markers with the greatest power of discrimination between sedentary and active elderly women. In addition, our results also suggest that regular physical exercise is important to maintain or maybe improve gait velocity and step length in a group of elderly women. Therefore, encouraging elderly subjects to practice physical exercise in order to attenuate and slow down the harmful effects of the ageing process and its consequences to gait is fundamental, as adequate mobility is essential for older adults to maintain the functional independence.

\section{REFERENCES}

1. Chaimowicz F. [Health of Brazilian elderly just before of the 21st century: current problems, forecasts and alternatives]. Rev Saude Publica 1997:31(2):184200.

2. World Health Organization. In Active ageing: a policy framework. WHO: Madrid (Spain); 2002.

3. Instituto Brasileiro de Geografia e Estatística. In Projeção da população do Brasil. IBGE; 2008.

4. US Census Bureau. International Data Base. Retrieved from: http:// www.census.gov/. Accessibility verified October, 2010.

5. Sattelmair JR, Pertman JH, Forman DE. Effects of physical activity on cardiovascular and noncardiovascular outcomes in older adults. Clin Geriatr Med 2009;25(4):677-6ix

6. Nelson ME, Rejeski WJ, Blair SN et al. Physical activity and public health in older adults: recommendation from the American College of Sports Medicine and the American Heart Association. Med Sci Sports Exerc 2007:39(8):1435-45.

7. Deley G, Kervio G, Van HJ et al. Effects of a one-year exercise training program in adults over 70 years old: a study with a control group. Aging Clin Exp Res 2007;19(4):310-5.

8. Simons R, Andel R. The effects of resistance training and walking on functional fitness in advanced old age. J Aging Health 2006;18(1):91-105.

9. Toraman NF, Erman A, Agyar E. Effects of multicomponent training on functional fitness in older adults. J Aging Phys Act 2004;12(4):538-53.

10. Vogel T, Brechat PH, Lepretre PM et al. Health benefits of physical activity in older patients: a review. Int J Clin Pract 2009;63(2):303-20.

11. Coimbra AM, Ricci NA, Coimbra IB, Costallat LT. Falls in the elderly of the Family Health Program. Arch Gerontol Geriatr 2010;51(3):317-22.

12. Callisaya ML, Blizzard L, Schmidt MD, McGinley JL, Srikanth VK. Sex modifies the relationship between age and gait: a population-based study of older adults. J Gerontol A Biol Sci Med Sci. 2008;63(2):165-70.

13. Lord SR, Lloyd DG, Nirui M et al. The effect of exercise on gait patterns in older women: a randomized controlled trial. J Gerontol A Biol Sci Med Sci 1996:51(2):M64-M70

14. Lopopolo RB, Greco M, Sullivan D, Craik RL, Mangione KK. Effect of therapeutic exercise on gait speed in community-dwelling elderly people: a meta-analysis. Phys Ther 2006;86(4):520-40.

15. Cao ZB, Maeda A, Shima N, Kurata H, Nishizono H. The effect of a 12-week combined exercise intervention program on physical performance and gait kinematics in community-dwelling elderly women. J Physiol Anthropol 2007;26(3):325-32.

16. Kim S, Lockhart T. Effects of 8 weeks of balance or weight training for the independently living elderly on the outcomes of induced slips. Int J Rehabil Res 2010;33(1):49-55

17. Bertolucci PH, Brucki SM, Campacci SR, Juliano Y. [The Mini-Mental State Examination in a general population: impact of educational status]. Arq Neuropsiquiatr 1994;52(1):1-7.

18. Bohannon RW. Reference values for the timed up and go test: a descriptive meta-analysis. J Geriatr Phys Ther 2006;29(2):64-8.

19. Podsiadlo D, Richardson S. The timed "Up \& Go": a test of basic functional mobility for frail elderly persons. J Am Geriatr Soc 1991;39(2):142-8.

20. Webster KE, Wittwer JE, Feller JA. Validity of the GAITRite walkway system for the measurement of averaged and individual step parameters of gait. Gait Posture 2005;22(4):317-21.

21. Menz HB, Latt MD, Tiedemann A, Mun San KM, Lord SR. Reliability of the GAITRite walkway system for the quantification of temporo-spatial parameters of gait in young and older people. Gait Posture 2004;20(1):20-5.

22. Perera S, Mody SH, Woodman RC, Studenski SA. Meaningful change and responsiveness in common physical performance measures in older adults. J Am Geriatr Soc 2006;54(5):743-9.

23. Harwood RH, Conroy SP. Slow walking speed in elderly people. BMJ 2009; 339:b4236.

24. Tiedemann A, Sherrington C, Lord SR. Physiological and psychological predictors of walking speed in older community-dwelling people. Gerontology 2005;51(6):390-5.

25. Fiser WM, Hays NP, Rogers SC et al. Energetics of walking in elderly people: factors related to gait speed. J Gerontol A Biol Sci Med Sci 2010;65(12):1332-7.

26. Callisaya ML, Blizzard L, Schmidt MD et al. A population-based study of sensorimotor factors affecting gait in older people. Age Ageing 2009;38(3):290-5.

27. Montero-Odasso M, Schapira M, Soriano ER et al. Gait velocity as a single predictor of adverse events in healthy seniors aged 75 years and older. J Gerontol A Biol Sci Med Sci 2005;60(10):1304-9.

28. Studenski S, Perera $S$, Wallace $D$ et al. Physical performance measures in the clinical setting. J Am Geriatr Soc 2003;51(3):314-22.

29. Verghese J, Holtzer R, Lipton RB, Wang C. Quantitative gait markers and incident fall risk in older adults. J Gerontol A Biol Sci Med Sci 2009:64(8):896-901.

30. Everitt BS, Dunn G. Applied multivariate data analysis. 2nd ed. London: Hodder Education, 2001 